\title{
Adsorption of blue copper on a natural and electrochemically treated bentonite
}

\author{
M. Hajjaji • Y. Mountassir · A. Benyaich
}

Received: 2 February 2014/ Accepted: 30 April 2014/Published online: 24 May 2014

(C) The Author(s) 2014. This article is published with open access at Springerlink.com

\begin{abstract}
Kinetics and equilibrium studies of the adsorption of blue copper on a natural (NC) and electrochemically treated (EMC) bentonite, taken in different experimental conditions, were carried out. Changes of the dye uptake versus operating factors were evaluated using response surface methodology (RSM). The kinetics at $5-50{ }^{\circ} \mathrm{C}$ and $\mathrm{pH}<10$ obeyed the pseudo-first-order equation. Beyond $\mathrm{pH} 10$, the pseudo-second-order equation also was suitable. The kinetics for $\mathrm{NC}$ was essentially controlled by external diffusion. However, both internal and external diffusion were the rate-limiting steps of the EMC kinetics. The NC isotherms were well described by the Langmuir model and the maximum uptake was around $21 \mathrm{mg} / \mathrm{g}$. In the case of EMC, the Freundlich equation was rather fitting. Dye adsorption on both sorbents was a nonspontaneous process $\left(2<\Delta G_{T}^{0}<8 \mathrm{~kJ} / \mathrm{mol}\right)$. According to the RSM results, $\mathrm{pH}$ had a negative impact on the dye adsorption and was the most influential factor in the case of EMC. For NC, the clay dose was rather the most important parameter.
\end{abstract}

Keywords Bentonite - Electrochemical treatment - Blue copper $\cdot$ Adsorption $\cdot$ Response surface methodology

M. Hajjaji ( $\varangle) \cdot$ Y. Mountassir · A. Benyaich

Laboratoire de Physico-chimie des Matériaux et Environnement, Unité Associée au CNRST (URAC 20), Département de Chimie, Faculté des Sciences Semlalia, Université Cadi Ayyad, B.P. 2390 Marrakech, Morocco

e-mail: hajjaji@uca.ma

\section{Introduction}

Dyestuffs in effluents engender water pollution and affect the photosynthesis process (Albanis et al. 2000). They can be successfully removed by commercial adsorbents (activated carbon and synthetic resins). However, these materials are expensive and very difficult to regenerate. Thus, low-cost adsorbents such as fly ash and mud (Wang et al. 2005), clays (Hajjaji et al. 2006; Atun et al. 2003; McKay et al. 1987), agricultural residues (Robinson et al. 2002), chitosan-based materials (Elwakeel et al. 2012; Elwakeel 2009) and diatomaceous earth (Al-Ghouti et al. 2003) were tested.

As anionic species, clay minerals especially those of the smectite group are able to remove cationic dyes from aqueous solutions (Gillman 2011; Crini 2006; Lagaly et al. 2006; Hajjaji et al. 2001; Yariv 2001). However, numerous dyes are anionic compounds and their spontaneous adsorption on clay minerals is limited if not impossible.

Much less attention has been paid to the adsorption of anionic dyes on electrochemically modified clays. The electrochemical treatment of clays may result in the change of particles polarization and the increase of porosity. Moreover, in the use of a sacrificial aluminum anode, cationic monomers and polymers might form in solution (Picard et al. 2000) and enter the interlayer space of swelling clay minerals. All these eventual phenomena could facilitate adsorption of anionic dyes on clay particles.

In this study, the kinetics of the adsorption of blue copper (anionic dye) on a natural and electrochemically treated bentonite was followed in different operating conditions. The influence of operating factors $(\mathrm{pH}$, contact time, clay dose and temperature) on the adsorption process was assessed using response surface methodology. The adsorption isotherms for both sorbents were established, and thermodynamic data were determined. 


\section{Materials and experimental procedures}

The basic raw clay, labeled NC, was from a Mio-Pliocene deposit sited at the east side of the high Atlas Mountain (Morocco) (Driouich 1993). It looked like a fuller's earth and was used in rustic cosmetic preparations. Its fine fraction (equivalent spherical diameter $<2 \mu \mathrm{m}$ ) represented $90 \%$. The specific surface area and cation exchange capacity determined using methylene blue (Hang and Brindley 1970) were $608 \mathrm{~m}^{2} / \mathrm{g}$ and $1.15 \mathrm{meq} / \mathrm{g}$, respectively.

The electrochemical treatment of the clay was carried out using the experimental assembly represented in Fig. 1. An aqueous dispersion composed of bentonite $(1 \mathrm{~g} / \mathrm{L})$ and $\mathrm{NaCl}(1 \mathrm{~g} / \mathrm{L})$ was placed in the electrochemical cell, consisting of a sacrificial aluminum anode, and experienced the current density $46.62 \mathrm{~A} / \mathrm{m}^{2}$ for $2 \mathrm{~h}$. The test was realized at $25{ }^{\circ} \mathrm{C}$ and $\mathrm{pH}=6-7$. The as-treated dispersion was centrifuged at 4,000 rpm, and the sediment, labeled EMC, was washed with distilled water to remove $\mathrm{Cl}^{-}$, then ovendried $24 \mathrm{~h}$ at $80{ }^{\circ} \mathrm{C}$.

The used blue copper (chemical formula: $\mathrm{C}_{21} \mathrm{H}_{16} \mathrm{~N}_{3}$ $\mathrm{S}_{4} \mathrm{Na}_{3} \mathrm{O}_{16} \mathrm{Cu}$; purity: $98 \%$ ) was supplied by a small textiledying plant located at El Jadida (Morocco). It was freely soluble in water, and its absorption band manifested at $560 \mathrm{~nm}$.

For the kinetics experiments, $100 \mathrm{~mL}$ of an aqueous dispersion, composed of $25 \mathrm{mg} / \mathrm{L}$ of blue copper and $0.8 \mathrm{~g}$ of $\mathrm{NC}$ or $0.6 \mathrm{~g}$ of EMC, was placed in a thermostated bath

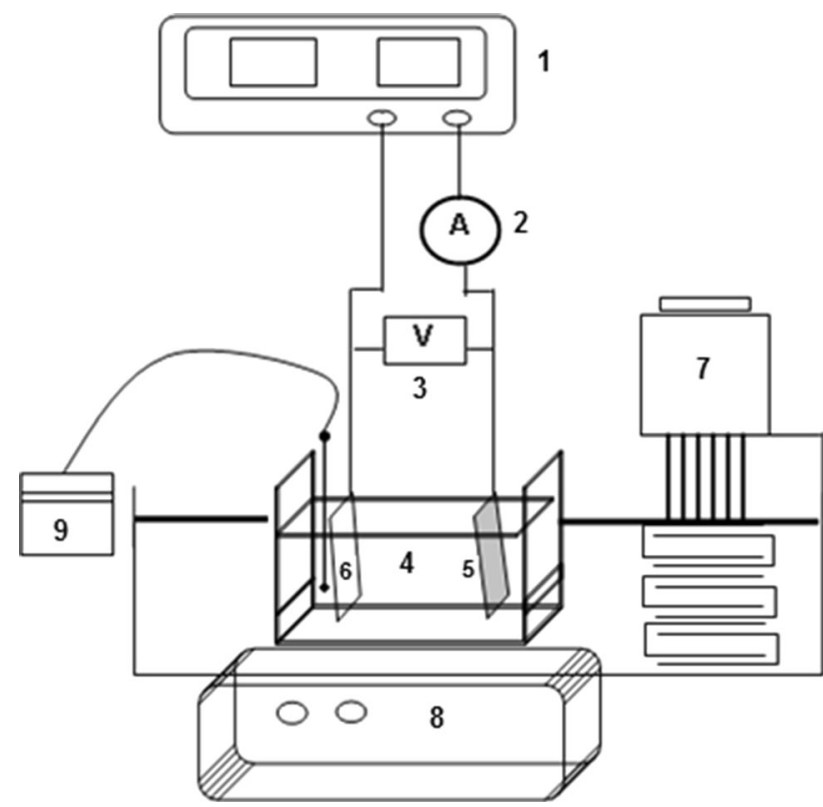

Fig. 1 Schematic representation of the experimental assembly used for the electrochemical treatment of the studied bentonite. $1 \mathrm{DC}$ power supply, 2 ammeter, 3 voltmeter, 4 electrochemical cell, 5 anode, 6 cathode, 7 thermostat, 8 stirring apparatus, $9 \mathrm{pH}$-meter $\left(5,15,25\right.$ or $\left.50{ }^{\circ} \mathrm{C}\right)$ and experienced a steady stirring. Samples were taken from the dispersion at regular time intervals and centrifuged at $6,000 \mathrm{rpm}$. The dye content in the supernatant was determined by means of a Spectronic 20 Genesys TM, operating at the wavelength $560 \mathrm{~nm}$, and using a pre-established linear curve expressing the Beer's law. The instantaneous amount of the adsorbed dye $\left(q_{t} ; \mathrm{mg} /\right.$ $\mathrm{g}$ of adsorbent) was related to the measured dye concentration $\left(C_{t} ; \mathrm{mg} / \mathrm{L}\right)$ as follows: $q_{t}=\left(C_{0}-C_{t}\right) \mathrm{V} / \mathrm{m}\left[C_{0}\right.$ initial dye concentration $(\mathrm{mg} / \mathrm{L}), V$ volume of solution $(\mathrm{L})$; $m$ sorbent mass $(\mathrm{g})]$. The effect of $\mathrm{pH}$ on the adsorption kinetics was tested in the range 4-12. Droplets of $\mathrm{H}_{2} \mathrm{SO}_{4}$ $(0.1 \mathrm{M})$ or $\mathrm{NaOH}(0.1 \mathrm{M})$ were occasionally added to maintain $\mathrm{pH}$ constant.

The equilibrium tests were carried out at different constant temperatures $\left(5,15,25\right.$ and $\left.50{ }^{\circ} \mathrm{C}\right)$. The characteristics of the used dispersions were similar to those mentioned in the kinetics study, except for the dye concentration, which was varied from 1 to $75 \mathrm{mg} / \mathrm{L}$. The contact time was $1 \mathrm{~h} 30 \mathrm{~min}$, largely exceeding the equilibrium time. The $\mathrm{pH}$ of solutions was naturally stabilized at 7.2 \pm 0.1 .

Adsorbents, before and after experiments, were analyzed by X-ray diffraction (XRD) and Fourier transform infrared (FT-IR). For XRD, a PHILIPS X'PertMPD diffractometer [generator voltage: $40 \mathrm{kV}$; tube current: $30 \mathrm{~mA}$; scan step size: $0.02^{\circ}$; time/step: $2 \mathrm{~s}$; anode: copper $(K \alpha=1.5418 \AA)$ ] was used. The FT-IR spectra were recorded with a Perkin Elmer spectrophotometer functioning in the range 4,000 and $400 \mathrm{~cm}^{-1}$. For this purpose, thin pastilles composed of adsorbent and $\mathrm{KBr}$ (about 96 mass \%) were shaped.

\section{Model presentation}

The equations expressing the variation of the dye uptake amount versus the operating factors $(\mathrm{pH}$, contact time, clay dose and temperature) for both sorbents were established by adopting the following polynomial model, which was successfully applied in various studies (e.g., Ferreira et al. 2003; Khalfaoui et al. 2006; Liu et al. 2004):

$$
\begin{aligned}
Y= & a_{0}+a_{1} X_{1}+a_{2} X_{2}+a_{3} X_{3}+a_{4} X_{4}+a_{11} X_{1}^{2}+a_{22} X_{2}^{2} \\
& +a_{33} X_{3}^{2}+a_{44} X_{4}^{2}+a_{12} X_{1} X_{2}+a_{13} X_{1} X_{3} \\
& +a_{14} X_{1} X_{4}+a_{23} X_{2} X_{3}+a_{24} X_{2} X_{4}+a_{34} X_{3} X_{4}
\end{aligned}
$$

$X_{1}, X_{2}, X_{3}$ and $X_{4}$ are the coded variables associated to $\mathrm{pH}$, contact time, clay dose and temperature, respectively. The coded variable $X_{i}$ is related to the natural variable $\left(x_{i}\right)$ as follows: $X_{i}=\left(x_{i}-x_{i}^{0}\right) / \Delta x_{i} ; x_{i}^{0}$ is the central value of the investigated range of $x_{i}$. $\Delta x_{i}$ is the variation step of $x_{i}$.

$a_{0}$ is a constant; $a_{1}, a_{2}, a_{3}$ and $a_{3}$ are the weights of $\mathrm{pH}$, contact time, clay dose and temperature, respectively. 
Coefficient $a_{i i}$ can be considered as a curve-shape parameter, and $a_{i j}$ expresses the interaction effect between $x_{i}$ and $x_{j}$ factors. The coefficients were determined by the least square regression using the Design-Expert software. For this purpose, 30 experiments included the replicated ones were realized.

The significance and the validity of the model were evaluated by the analysis of variance (ANOVA). The above software was used for the statistical data determination.

\section{Results and discussion}

Mineralogical and chemical characterization of the used sorbents

The studied raw clay (NC) was composed of montmorillonite, carbonates (calcite and dolomite), quartz and hematite (Fig. 2, NC) together with minor amounts of aliphatic organic compounds and kaolinite (Fig. 3). As a result of the electrochemical treatment, the intensities of
Fig. 2 X-ray diffraction patterns of the studied natural clay (NC), electrochemically modified clay (EMC), natural clay-blue copper (NC-D) and the electrochemically modified clay-blue copper (EMC-D) residues, and the blue copper (D). $M$ montmorillonite, $Q$ quartz, $C$ calcite, $D o$ dolomite, $H$ hematite
Fig. 3 FT-Infrared spectra of $\mathrm{NC}, \mathrm{EMC}$, and NC-dye and EMC-dye residues. $K$ kaolinite, $M$ montmorillonite, $W$ water, $O M$ organic matter,

$C$ carbonates (calcite/dolomite), $Q$ quartz
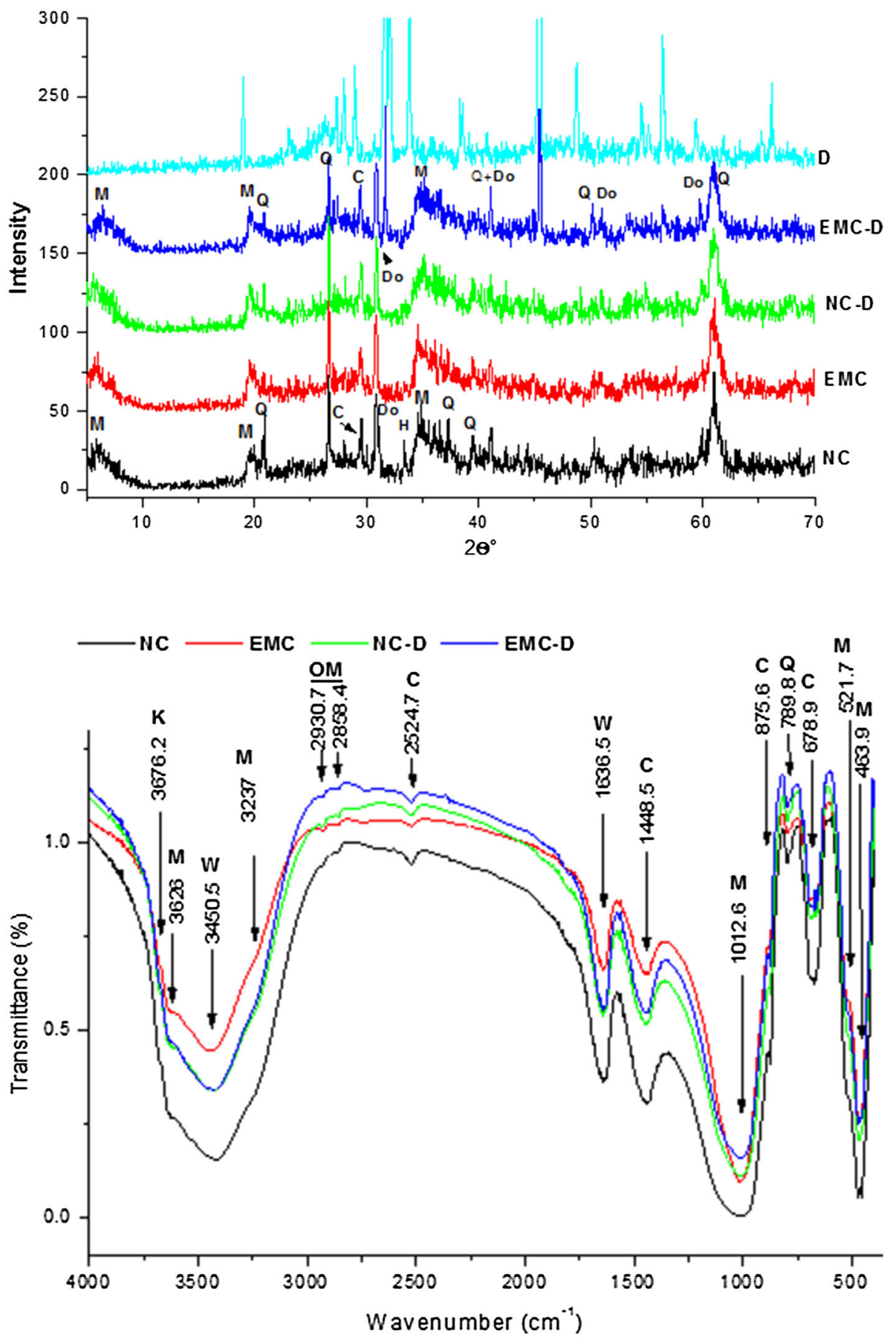
Table 1 Elemental compositions (wt $\%$ ) of the studied sorbents

\begin{tabular}{lllllllll}
\hline & $\mathrm{Mg}$ & $\mathrm{Al}$ & $\mathrm{Si}$ & $\mathrm{S}$ & $\mathrm{Cl}$ & $\mathrm{K}$ & $\mathrm{Ca}$ & $\mathrm{Fe}$ \\
\hline $\mathrm{NC}$ & 22.06 & 4.15 & 52.59 & 5.36 & 0.82 & 1.90 & 11.24 & 1.88 \\
$\mathrm{EMC}$ & 23.88 & 5.25 & 57.77 & 0.96 & 0.63 & 1.23 & 8.70 & 1.59 \\
\hline
\end{tabular}

the X-ray reflections of calcite, quartz and montmorillonite decreased when those of hematite almost vanished (Fig. 2, EMC). Quartz and montmorillonite experienced a partial dissolution and/or transformation into amorphous compounds. The basal distance of montmorillonite $\left(d_{001}\right)$ evolved from 14.21 to $14.98 \AA$ A. This slight swelling could be due to a limited intercalation of water molecules in the interlayer space (Holtzapffel 1985).

Considering the chemical compositions of $\mathrm{NC}$ and EMC (Table 1), it is derived that calcium, sulfur, potassium and iron were partially leached from the modified clay. Calcium was the most leachable element. It was essentially derived from dissolved calcite, which proportion was estimated to be $30 \%$.

Referring to the reported results dealing with the electrocoagulation processes using aluminum as a sacrificial electrode, species such as $\mathrm{Al}(\mathrm{OH})_{3}$ and/or $\mathrm{Al}(\mathrm{OH})_{4}^{-}$could be formed in solution (Kobya et al. 2003; Picard et al. 2000). Based on the analytical data (Table 1) and the FTIR analyses (Fig. 3), no aluminum-derivative species were present in the sediment, likely because of leaching or formation of a film at the anode surface.

Considering the amounts of silica in NC and EMC (Table 1) and seeing that the quartz amount decreased as a result of the electrochemical treatment, quartz partially transformed to amorphous silica, and the sediment of EMC manifested a homogeneous texture.

Effect of the adsorbent content on the dye uptake

The dye uptake by both adsorbents increased almost linearly with the increase of the adsorbent dose (Fig. 4), and the slopes of the curves were quasi-similar $\left(2.4 \mathrm{mg} \mathrm{L} / \mathrm{g}^{2}\right)$. The uptake increase was linked to the accessibility to supplementary active sites. Nevertheless, beyond a threshold value of the clay dose (about 7.8 and $6.5 \mathrm{~g} / \mathrm{L}$ of $\mathrm{NC}$ and EMC, respectively), the dye-retained amount remained quasi-constant. In such concentrated dispersions, the quasi-totality of additional potential adsorption sites was likely not accessible because of particles aggregation, due to the development of intense attractive electrostatic forces. The dye uptake was relatively high for EMC (Fig. 4), which suggested that the clay treatment produced new active adsorption sites.

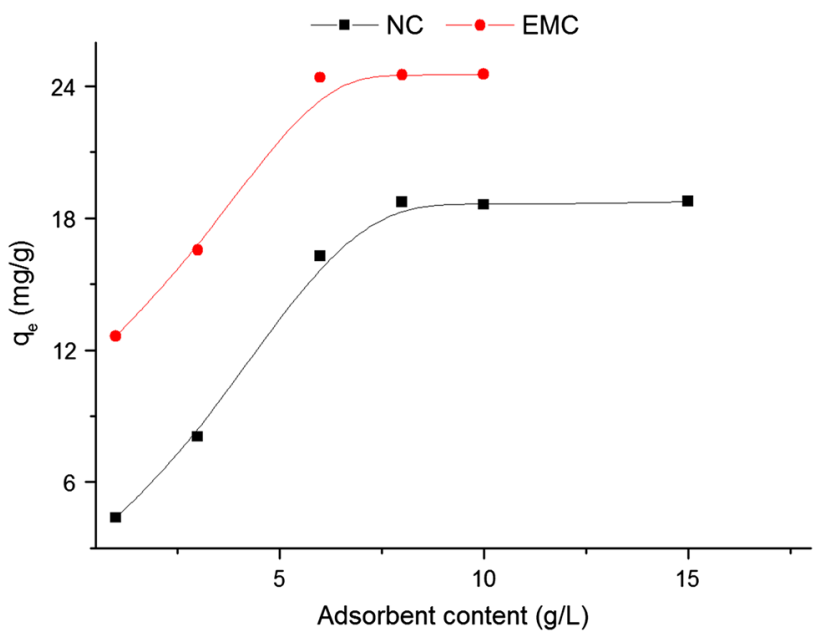

Fig. 4 Variation of the dye uptake by NC and EMC versus sorbent dose

Kinetics study

\section{Effects of contact time and temperature}

Typical curves showing the evolution of the dye uptake at different temperatures versus contact time for $\mathrm{NC}$ and EMC are reported in Fig. 5. The adsorption process was fast for both sorbents and the equilibrium contact time was $<25 \mathrm{~min}$, except for the lowest operating temperature.

The kinetics data were examined using the pseudo-firstorder equation $\left(\operatorname{Ln}\left[\left(q_{\mathrm{e}}-q_{t}\right) / q_{\mathrm{e}}\right]=-k t ; q_{\mathrm{e}}\right.$ and $q_{t}$ are the uptake amounts at equilibrium and $t$ instant; $k$ is the rate constante) as well as the pseudo-second-order equation (1/ $\left(q_{\mathrm{e}}-q_{t}\right)=1 / q_{\mathrm{e}}+k t$; the parameters have the same meaning) (Ho and McKay 1998). The best fitting was observed by applying the pseudo-first-order equation. The rate constants and the fitting coefficients for tested temperatures are given in Table 2. It was derived that dye adsorption was more rapid for $\mathrm{NC}$, except at the lowest temperature. It may be noted that the plot of $\operatorname{Ln} k_{1}=f(1 /$ $T$ ) (not shown) did not follow a linear curve, indicating that the activation energy was not constant in the investigated range of temperatures.

To have a deep insight into the kinetics process, the internal (Eq. 1) and external (Eq. 2) diffusion models (AlDegs et al. 2006; Ho et al. 2000) were tested:

$q_{t}=k_{d} t^{0.5}$

$k_{d}$ is the intra-particle diffusion rate $\left(\mathrm{mg} / \mathrm{g} \min ^{0.5}\right)$.

$\operatorname{Ln}\left(C_{t} / C_{o}\right)=-k_{f}(A / V) t$

$k_{f}$ is the external diffusion coefficient $(\mathrm{cm} / \mathrm{s})$, and $A$ the external surface area to the volume $(V)$ of solution. 

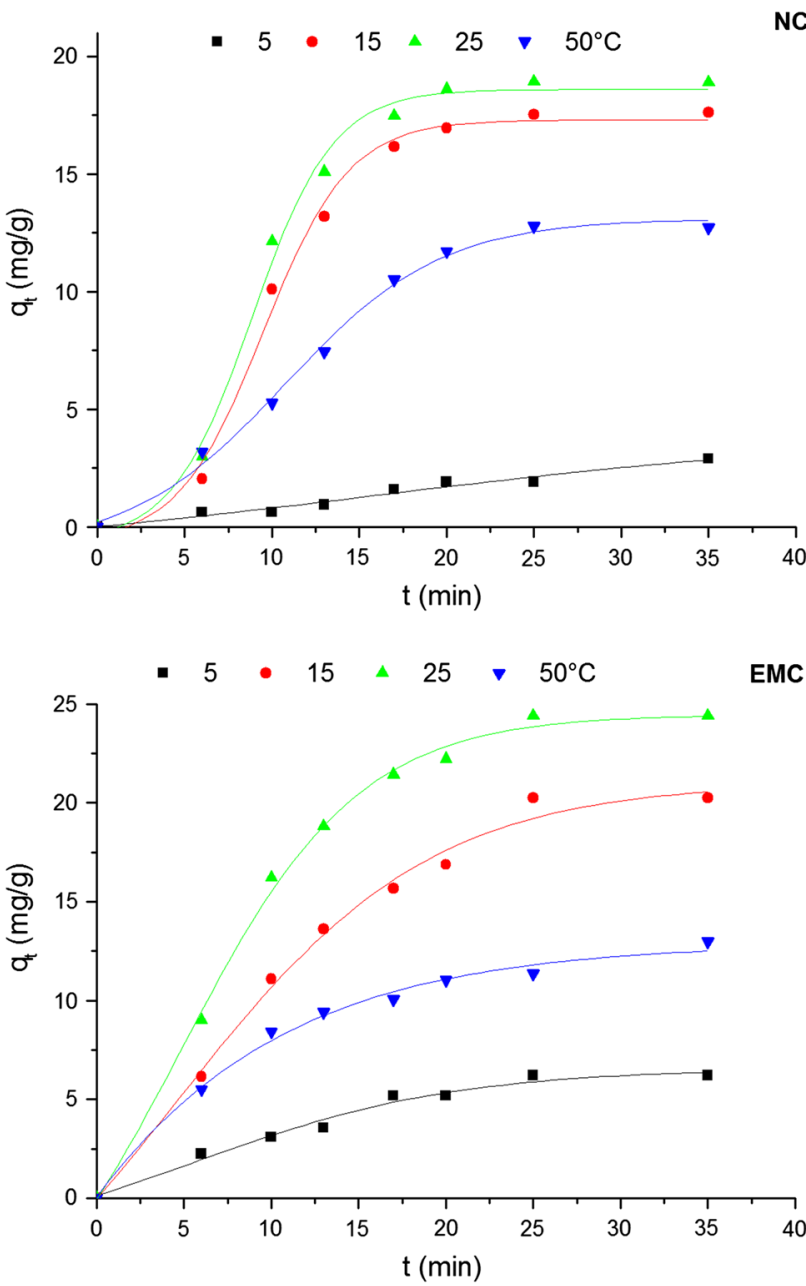

Fig. 5 Kinetics curves of dye adsorption on NC (at different temperatures)

Table 2 Pseudo-first-order rate constants and fitting coefficients related to the kinetics of the dye adsorption on NC and EMC realized at different temperatures

\begin{tabular}{llllll}
\hline & $T(\mathrm{~K})$ & 278 & 288 & 298 & 323 \\
\hline NC & $k\left(10^{-2} / \mathrm{min}\right)$ & 5.4 & 26.2 & 26.8 & 16.2 \\
& $R^{2}$ & 0.945 & 0.988 & 0.979 & 0.967 \\
EMC & $k\left(10^{-2} / \mathrm{min}\right)$ & 9.6 & 9.0 & 12.6 & 9.9 \\
& $R^{2}$ & 0.963 & 0.996 & 0.994 & 0.994 \\
\hline
\end{tabular}

The plots of Eqs. (1) and (2) using the kinetics data relevant to NC are shown in Fig. 6a. As the linear curves associated to the internal diffusion model $\left(q_{t}=f\left(t^{0.5}\right)\right)$ did not go through the origin, the external diffusion was considered as the rate-limiting step (Al-Degs et al. 2006). The determined internal and external diffusion coefficients are reported in Table 3. Except for the highest temperature, the suitability of the external diffusion model was supported by the high values of the fitting coefficient (Table 3). In the case of EMC, the curves relevant to the intra-particle diffusion model passed by the origin (Fig. 6b), and the models suitability was evaluated by comparing the correlation coefficients values (Table 3). It was deduced that the rate-controlling step depended on temperature: at $323 \mathrm{~K}$ the intra-particle diffusion was the most influencing process. At 278 and $288 \mathrm{~K}$, diffusion across the liquid boundary layer was rather the main controlling phenomenon. At $298 \mathrm{~K}$, both diffusion mechanisms were comparable.

\section{Effect of $p H$}

Adsorption kinetics curves plotted at different $\mathrm{pH}$ are shown in Fig. 7. The change of $\mathrm{pH}$ did not have an appreciable effect on the equilibrium time, but it affected the maximum uptake (Fig. 8). Beyond about 8.7, which was close to $\mathrm{pH}$ of $\mathrm{NC}$, the maximum uptake declined. This could be linked to intense negative polarization of clay particles, and consequently to dye species repulsion. Details related to this process are reported hereafter.

The plots of the aforementioned kinetics equations (not shown) and the correlation coefficient values (Table 4) allowed to deduce that the kinetics of the dye adsorption on both sorbents well followed the pseudofirst-order equation for $\mathrm{pH}<10$, and the rate constants for $\mathrm{NC}$ were slightly higher (Table 4). For $\mathrm{pH}=10$, the kinetics data related to $\mathrm{NC}$ and EMC might be rather described by both equations. For $\mathrm{pH}=12$, the well-fitting kinetic equation for the data of $\mathrm{NC}$ was the pseudosecond-order equation.

Regardless the correlation coefficients in Table 5, and because the plots of $q_{t}=f\left(t^{0.5}\right)$ related to NC did not pass through the origin, the intra-particle diffusion could not be the rate-controlling step. Thus, dye adsorption was essentially controlled by diffusion through the liquid film. For EMC, the curves $q_{t}=f\left(t^{0.5}\right)$ and $\operatorname{Ln}\left(C_{t} / C_{\mathrm{o}}\right)=f(t)$ together with $R^{2}$ values (Table 5) showed that the kinetics was also controlled by film diffusion, but the transfer coefficient was slightly lower than that found for NC (Table 5).

\section{Modeling study}

The experimental conditions of the runs arranged by the central composite design (CCD) and their corresponding experimental responses $\left(Y_{i, \text { meas }} ; \mathrm{mg} / \mathrm{g}\right)$ for both adsorbents are given in Table 6 . The determined equations expressing the variation of the dye uptake amount versus the coded variables related to $\mathrm{pH}$, contact time, clay dose and temperature are as follows: 

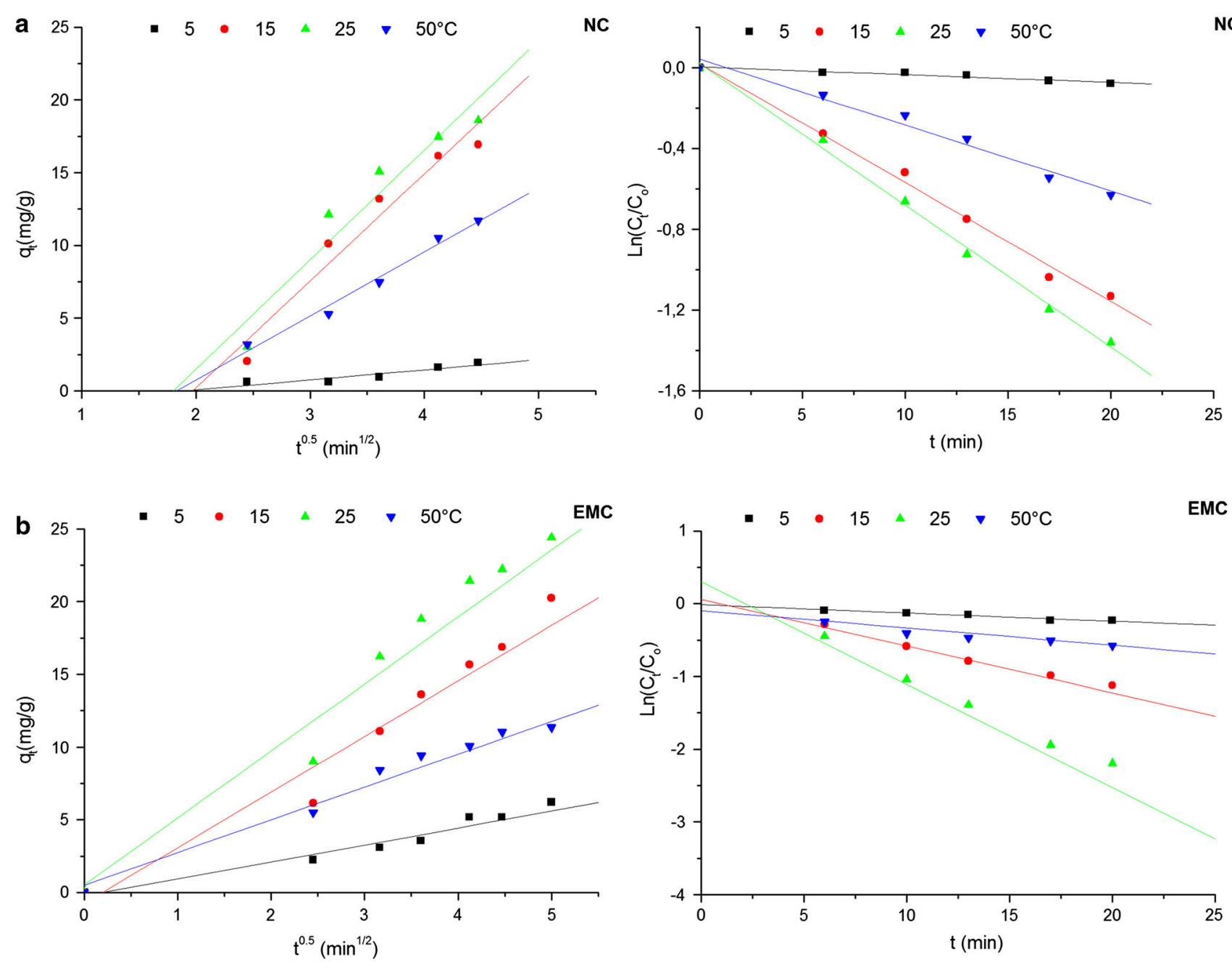

Fig. 6 Variations of the instantaneous uptake amount $\left(q_{t}\right)$ and $\operatorname{Ln}\left(C_{t} / C_{0}\right)$, taken at different temperatures, against contact time for both considered sorbents

Table 3 Internal and external diffusion coefficients and correlation coefficients determined at different temperatures

\begin{tabular}{llllll}
\hline & $T(\mathrm{~K})$ & 278 & 288 & 298 & 323 \\
\hline $\mathrm{NC}$ & $K_{d}(\mathrm{mg} / \mathrm{g} \mathrm{min})$ & 0.69 & 7.36 & 7.53 & 4.41 \\
& $R^{2}$ & 0.926 & 0.973 & 0.962 & 0.991 \\
& $K_{f}\left(10^{-7} \mathrm{~cm} / \mathrm{s}\right)$ & 0.8 & 12.1 & 14.4 & 6.7 \\
& $R^{2}$ & 0.969 & 0.996 & 0.998 & 0.988 \\
$\mathrm{EMC}$ & $K_{d}(\mathrm{mg} / \mathrm{g} \mathrm{min})$ & 1.17 & 3.82 & 4.60 & 2.25 \\
& $R^{2}$ & 0.977 & 0.980 & 0.971 & 0.988 \\
& $K_{f}\left(10^{-7} \mathrm{~cm} / \mathrm{s}\right)$ & 5.25 & 0.30 & 0.66 & 0.11 \\
& $R^{2}$ & 0.989 & 0.991 & 0.972 & 0.949 \\
\hline
\end{tabular}

$$
\begin{aligned}
Y_{1}= & +14.53-2.03 X_{1}+2.47 X_{2}+3.46 X_{3}+0.26 X_{4} \\
& -0.42 X_{1} X_{2}-0.34 X_{1} X_{3}-0.67 X_{1} X_{4}-0.28 X_{2} X_{3} \\
& -0.74 X_{2} X_{4}+0.35 X_{3} X_{4}-0.22 X_{1}^{2}-1.15 X_{2}^{2} \\
& -0.99 X_{3}^{2}-1.60 X_{4}^{2}
\end{aligned}
$$

$$
\begin{aligned}
Y_{2}= & +15.47-3.37 X_{1}+2.75 X_{2}+2.53 X_{3}+0.70 X_{4} \\
& -0.46 X_{1} X_{2}-0.20 X_{1} X_{3}-0.29 X_{1} X_{4}-1.10 X_{2} X_{3} \\
& +0.20 X_{2} X_{4}+0.89 X_{3} X_{4}+1.07 X_{1}^{2}-0.51 X_{2}^{2} \\
& -0.48 X_{3}^{2}-1.04 X_{4}^{2}
\end{aligned}
$$

The accuracy of the model was checked based on the statistical data given in Table 7. The higher $F$ values and correlation coefficients (Aleboyeh et al. 2008; Yetilmezsoy et al. 2009), and the smaller standard deviation (SD) allowed to confirm the model suitability. As a matter of fact, only 3.6 and $2.3 \%$ of the variations of the dye uptake retention by $\mathrm{NC}$ and EMC respectively could not be explained by the model.

Considering the $Y_{1}$ equation, the influence of the test factors on the dye retention followed the order: clay dose $>$ contact time $>\mathrm{pH}>T$. In fact, the dye uptake enhanced much more with the increase of adsorption sites, which amount should rise with the increase of the clay dose. Nevertheless, there was a limit due to particles 

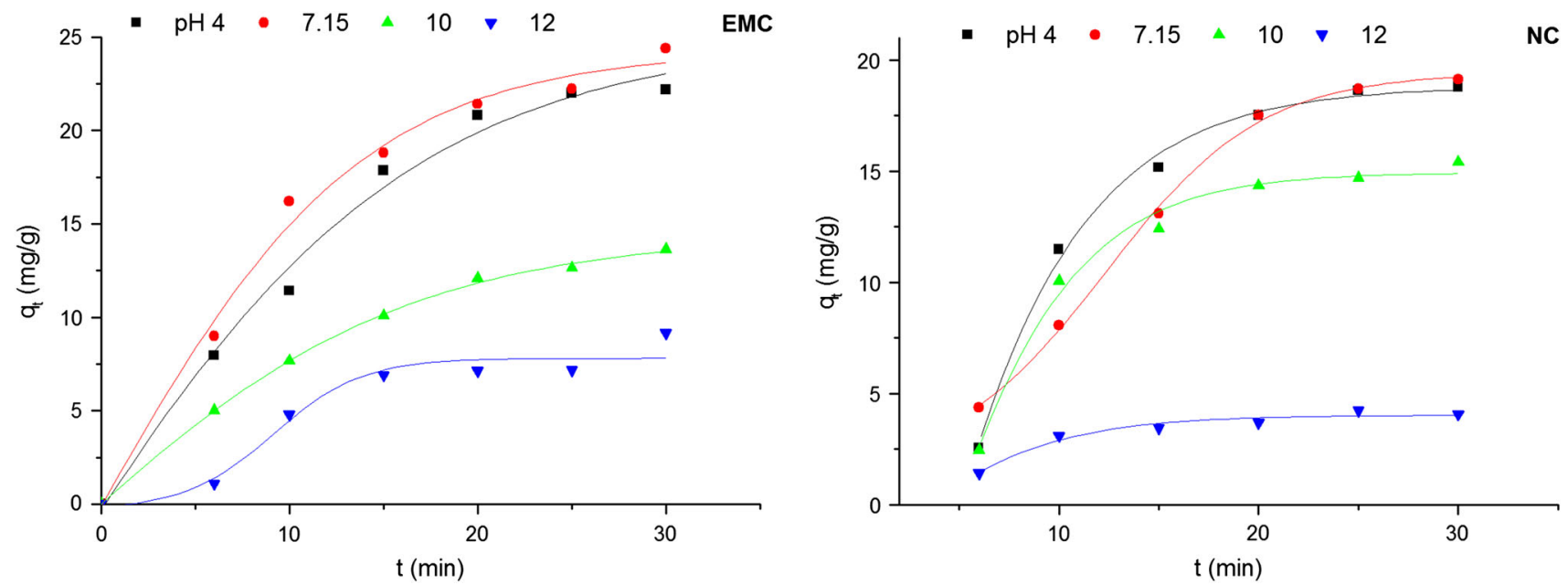

Fig. 7 Kinetics curves of the dye adsorption on $\mathrm{NC}$ and EMC at different $\mathrm{pH}$

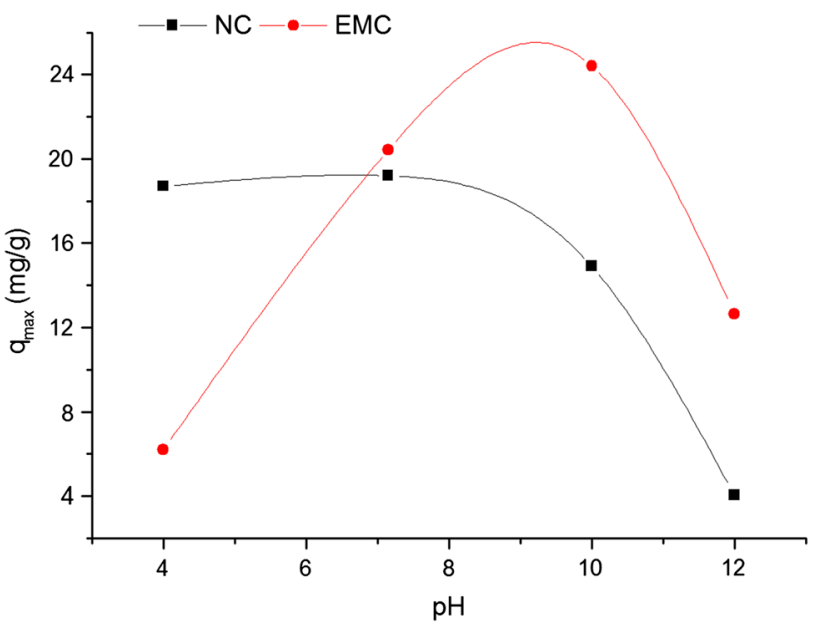

Fig. 8 Change of the maximum uptake of the dye by NC and EMC versus $\mathrm{pH}$

Table 4 Pseudo-first- and pseudo-second-order rate constants and fitting coefficients related to the kinetics of the dye adsorption on NC and EMC realized at different $\mathrm{pH}$

\begin{tabular}{llllll}
\hline & $\mathrm{pH}$ & 4 & 7.15 & 10 & 12 \\
\hline $\mathrm{NC}$ & $k_{1}\left(10^{-2} / \mathrm{min}\right)$ & 18.2 & 18.3 & 21.4 & 13.5 \\
& $R^{2}$ & 0.997 & 0.976 & 0.995 & 0.968 \\
& $k_{2}\left(10^{-3} \mathrm{~g} / \mathrm{mg}^{\prime} \mathrm{min}\right)$ & 2.79 & 0.30 & 4.71 & 29.5 \\
& $R^{2}$ & 0.989 & 0.758 & 0.996 & 0.991 \\
$\mathrm{EMC}$ & $k_{1}\left(10^{-2} / \mathrm{min}\right)$ & 13.7 & 10.6 & 10.7 & 13.9 \\
& $R^{2}$ & 0.964 & 0.994 & 0.986 & 0.961 \\
& $k_{2}\left(10^{-3} \mathrm{~g} / \mathrm{mg} / \mathrm{min}\right)$ & 0.48 & 1.56 & 1.74 & 9.68 \\
& $R^{2}$ & 0.928 & 0.956 & 0.986 & 0.959
\end{tabular}

$k_{1}$ and $k_{2}$ are the rate constants of the pseudo-first- and pseudo-second-order equations, respectively

agglomeration. Also, but at a lesser degree, the dyeretained amount increased with the increase of the contact time. This may had a relation with the hindrance
Table 5 Internal and external diffusion coefficients and correlation coefficients determined at different $\mathrm{pH}$

\begin{tabular}{llllll}
\hline & $\mathrm{pH}$ & 4 & 7.15 & 10 & 12 \\
\hline $\mathrm{NC}$ & $K_{d}(\mathrm{mg} / \mathrm{g} \mathrm{min})$ & 5.09 & 5.26 & 3.91 & 0.82 \\
& $R^{2}$ & 0.928 & 0.978 & 0.916 & 0.912 \\
& $K_{f}\left(10^{-5} \mathrm{~cm} / \mathrm{s}\right)$ & 1.1 & 1.2 & 0.7 & 0.1 \\
& $R^{2}$ & 0.946 & 0.977 & 0.919 & 0.875 \\
$\mathrm{EMC}$ & $K_{d}(\mathrm{mg} / \mathrm{g} \mathrm{min})$ & 5.08 & 4.67 & 2.86 & 2.29 \\
& $R^{2}$ & 0.966 & 0.964 & 0.987 & 0.934 \\
& $K_{f}\left(10^{-6} \mathrm{~cm} / \mathrm{s}\right)$ & 4.5 & 4.2 & 1.2 & 0.7 \\
& $R^{2}$ & 0.993 & 0.988 & 0.983 & 0.871 \\
\hline
\end{tabular}

experienced by dye species to go through the boundary layer for reaching the active sites. Except for $\mathrm{pH}$, the test factors had positive impacts on the uptake amount, i.e., dye fixation increased with the increase of the factors. The negative impact of $\mathrm{pH}$ could be explained by the fact that in alkaline solutions, abundant negative sites developed on the clay particles and repulsed the anionic dye species.

The interactions between the factors were antagonistic (Fig. 9a-e), except that manifested between temperature and clay dose, which was synergetic (Fig. 9f). The weights of the interactions were less significant as compared to those of the factors.

In view of the algebraic values of the linear terms of the $\mathrm{Y}_{2}$ equation, the nature of the effects (positive/negative) of the factors on the dye uptake by EMC were similar to those seen for $\mathrm{NC}$, but the weights of the effects were different: $\mathrm{pH}>$ contact time $>$ clay dose $>T$. The plots showing the interactions between the factors are given in Fig. 10. The unique difference with the $\mathrm{NC}$ case was the synergetic effect manifested between the contact time and temperature (Fig. 10e). 
Table 6 Central composite design matrix of four test variables in coded and natural variables, and measured responses $\left(Y_{i, \text { meas }}\right)$ for NC and EMC sorbents

\begin{tabular}{|c|c|c|c|c|c|c|c|c|c|c|}
\hline Run No. & $X_{1}$ & $X_{2}$ & $X_{3}$ & $X_{4}$ & $\mathrm{pH}$ & $t(\min )$ & $C(\mathrm{~g} / \mathrm{L})$ & $T(\mathrm{~K})$ & $Y_{1, \text { meas }}(\mathrm{mg} / \mathrm{g})$ & $Y_{2, \text { meas }}(\mathrm{mg} / \mathrm{g})$ \\
\hline 1 & -1 & 1 & -1 & -1 & 6 & 28 & 3 & 16 & 12.16 & 19.10 \\
\hline 2 & 0 & 0 & 0 & 0 & 8 & 21 & 6 & 28 & 14.11 & 15.32 \\
\hline 3 & 1 & 1 & -1 & -1 & 10 & 28 & 3 & 16 & 9.20 & 13.10 \\
\hline 4 & -1 & 1 & -1 & 1 & 6 & 28 & 3 & 39 & 11.45 & 19.74 \\
\hline 5 & 0 & 0 & 0 & 2 & 8 & 21 & 6 & 50 & 9.09 & 13.10 \\
\hline 6 & -1 & 1 & 1 & -1 & 6 & 28 & 8 & 16 & 18.86 & 21.00 \\
\hline 7 & 1 & -1 & -1 & 1 & 10 & 13 & 3 & 39 & 3.11 & 4.70 \\
\hline 8 & 0 & 2 & 0 & 0 & 8 & 35 & 6 & 28 & 15.03 & 18.71 \\
\hline 9 & -2 & 0 & 0 & 0 & 4 & 21 & 6 & 28 & 18.01 & 26.42 \\
\hline 10 & 2 & 0 & 0 & 0 & 12 & 21 & 6 & 28 & 9.34 & 12.80 \\
\hline 11 & 0 & 0 & 0 & 0 & 8 & 21 & 6 & 28 & 15.09 & 15.32 \\
\hline 12 & 0 & 0 & 0 & -2 & 8 & 21 & 6 & 5 & 7.26 & 9.26 \\
\hline 13 & 1 & 1 & -1 & 1 & 10 & 28 & 3 & 39 & 6.09 & 11.59 \\
\hline 14 & -1 & 1 & 1 & 1 & 6 & 28 & 8 & 39 & 19.09 & 24.76 \\
\hline 15 & 1 & -1 & -1 & -1 & 10 & 13 & 3 & 16 & 3.09 & 6.10 \\
\hline 16 & 0 & 0 & 0 & 0 & 8 & 21 & 6 & 28 & 14.09 & 15.32 \\
\hline 17 & -1 & -1 & -1 & -1 & 6 & 13 & 3 & 16 & 4.28 & 11.10 \\
\hline 18 & 0 & -2 & 0 & 0 & 8 & 6 & 6 & 28 & 4.93 & 7.84 \\
\hline 19 & 1 & -1 & 1 & -1 & 10 & 13 & 8 & 16 & 10.03 & 11.50 \\
\hline 20 & 0 & 0 & 0 & 0 & 8 & 21 & 6 & 28 & 14.41 & 15.92 \\
\hline 21 & 0 & 0 & 2 & 0 & 8 & 21 & 10 & 28 & 17.09 & 18.40 \\
\hline 22 & 1 & 1 & 1 & 1 & 10 & 28 & 8 & 39 & 13.09 & 16.31 \\
\hline 23 & -1 & -1 & 1 & -1 & 6 & 13 & 8 & 16 & 11.49 & 17.10 \\
\hline 24 & -1 & -1 & 1 & 1 & 6 & 13 & 8 & 39 & 16.28 & 19.87 \\
\hline 25 & 0 & 0 & -2 & 0 & 8 & 21 & 1 & 28 & 4.09 & 8.43 \\
\hline 26 & 1 & 1 & 1 & -1 & 10 & 28 & 8 & 16 & 14.16 & 13.10 \\
\hline 27 & 1 & -1 & 1 & 1 & 10 & 13 & 8 & 39 & 10.09 & 13.42 \\
\hline 28 & 0 & 0 & 0 & 0 & 8 & 21 & 6 & 28 & 15.09 & 15.32 \\
\hline 29 & 0 & 0 & 0 & 0 & 8 & 21 & 6 & 28 & 14.41 & 15.62 \\
\hline 30 & -1 & -1 & -1 & 1 & 6 & 13 & 3 & 39 & 6.57 & 10.76 \\
\hline
\end{tabular}

Table 7 Analysis of variance (ANOVA) for the adopted quadratic models and supplementary statistical data

\begin{tabular}{llllll}
\hline & $F$ value & Prob $>F$ & $R^{2}$ & Adj $R^{2}$ & SD** $^{* *}$ \\
\hline NC & 179.6 & $<0.0001^{*}$ & 0.964 & 0.969 & 0.71 \\
EMC & 396.02 & $<0.0001^{*}$ & 0.977 & 0.975 & 0.65 \\
\hline
\end{tabular}

* Significant at Prob $\leq 0.05$

** Standard deviation

Isotherms and thermodynamic data

As shown in Fig. 11, the shapes of the adsorption isotherms of NC and EMC were quite different, and saturation of $\mathrm{NC}$ particles required lower dye contents $\left(C_{\mathrm{e}}<20 \mathrm{mg} / \mathrm{L}\right)$. These let to think that interactions between dye species and adsorbents particles were dissimilar.
The plots (not shown) of the linear forms of the Langmuir equation $\left[q_{\mathrm{e}}=K_{\mathrm{L}} C_{\mathrm{e}} q_{\mathrm{m}} /\left(1+K_{\mathrm{L}} C_{\mathrm{e}}\right) ; q_{\mathrm{e}}\right.$ :equilibrium uptake $(\mathrm{mg} / \mathrm{g}) ; q_{\mathrm{m}}$ :maximum uptake $(\mathrm{mg} / \mathrm{g})$; $K_{\mathrm{L}}:$ Langmuir constant $\left.(\mathrm{L} / \mathrm{mg})\right]$ and Freundlich equation $\left(q_{\mathrm{e}}=K_{\mathrm{F}}\left(C_{\mathrm{e}}\right)^{1 / n} ; q_{\mathrm{e}}(\mathrm{mg} / \mathrm{g}) ; K_{\mathrm{F}}\left(\mathrm{mg}^{(n-1) / n} / \mathrm{g} \mathrm{L}^{n}\right)\right.$ and $\mathrm{n}$ are constants) together with the values of the linear correlation coefficients (Table 8) allowed to deduce that NC isotherms were well described by the Langmuir model while those of EMC well fitted the Freundlich isotherm. Values of the models parameters are given in Table 8. The dye adsorption on both sorbents was favored since the equilibrium dimensionless parameter $R_{\mathrm{L}}\left(R_{\mathrm{L}}=1 /\left(1+K_{\mathrm{L}} C_{\mathrm{o}}\right), C_{\mathrm{o}}\right.$ : maximal initial concentration of dye) and the Freundlich constant $(1 / n)$ were $<1$ (Hall and Vermeylem 1966; Yeddou and Bensmaili 2005). 

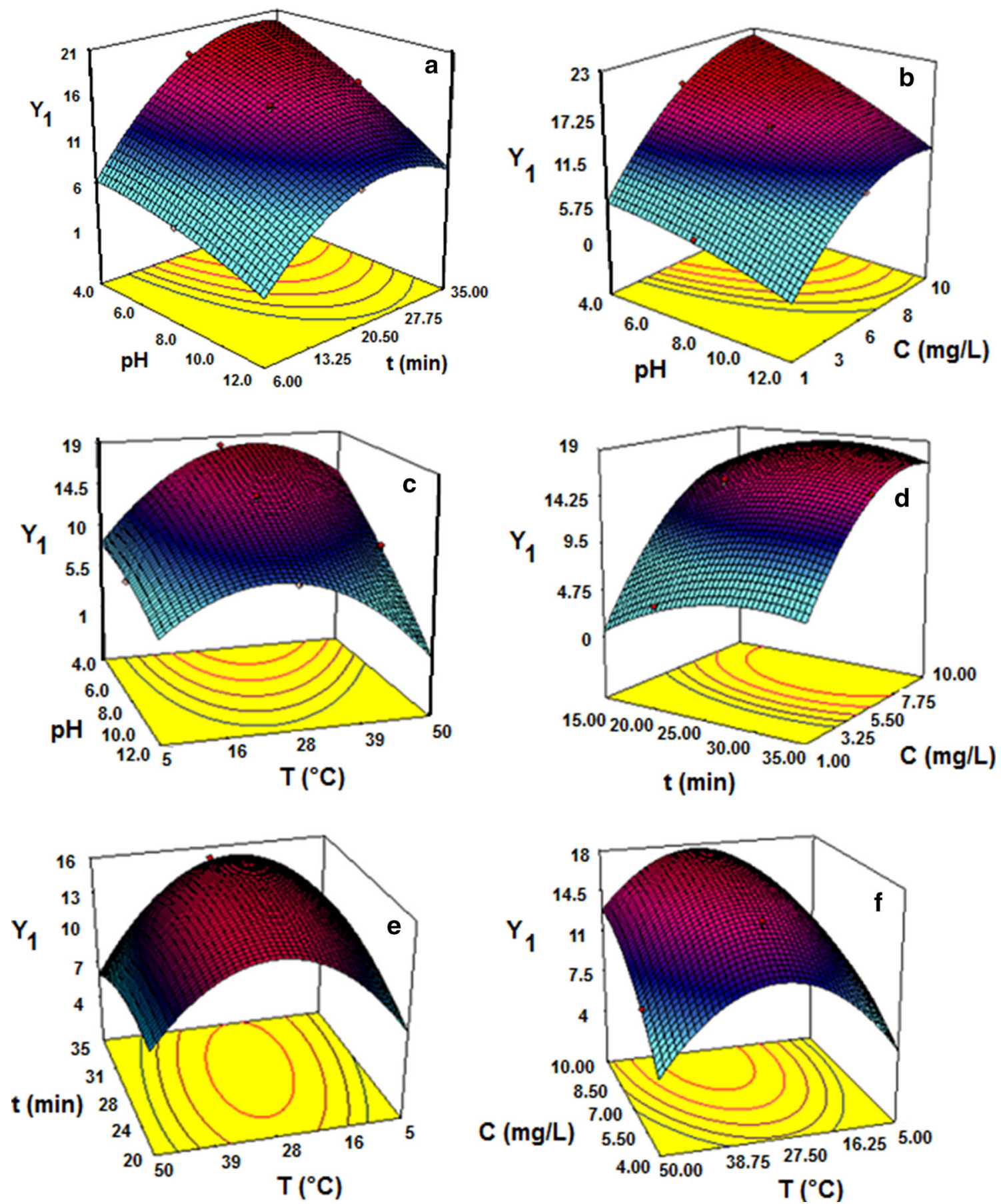

Fig. 9 Response surface plots related to the dye uptake by NC (hold values: $\mathrm{pH}=8 ; T=27.5^{\circ} \mathrm{C} ; C=6 \mathrm{mg} / \mathrm{L} ; t=20.5 \mathrm{~min}$ )

The suitability of the models also was assessed by the Marquardt's percent standard deviation (MPSD) (Porter et al. 1999):

$100\left(\sqrt{\frac{1}{p-n} \sum_{i=1}^{p}\left[\frac{\left(q_{\mathrm{e}, \text { meas }}-q_{\mathrm{e}, \mathrm{calc}}\right)_{i}^{2}}{q_{\mathrm{e}, \text { means }}}\right]}\right)$

$p$ : number of experimental measurements; $n$ : number of isotherm parameters $(2) ; q_{\mathrm{e}}$,meas and $q_{\mathrm{e}}$,calc are the measured and calculated uptake amounts at equilibrium.
The MPSD values are reported in Table 9. In agreement with the above findings, the NC isotherms well followed the Langmuir equation. However, a discrepancy was observed for EMC results. Referring to MPSD values, the best fitting model for the isotherm at $298 \mathrm{~K}$ should be the Langmuir model, and the isotherm at $288 \mathrm{~K}$ could be described by both models.

As the NC isotherms obeyed the Langmuir model, the Gibbs free energy $\left(\Delta G_{T}^{0}\right)$ was calculated from the relation: 

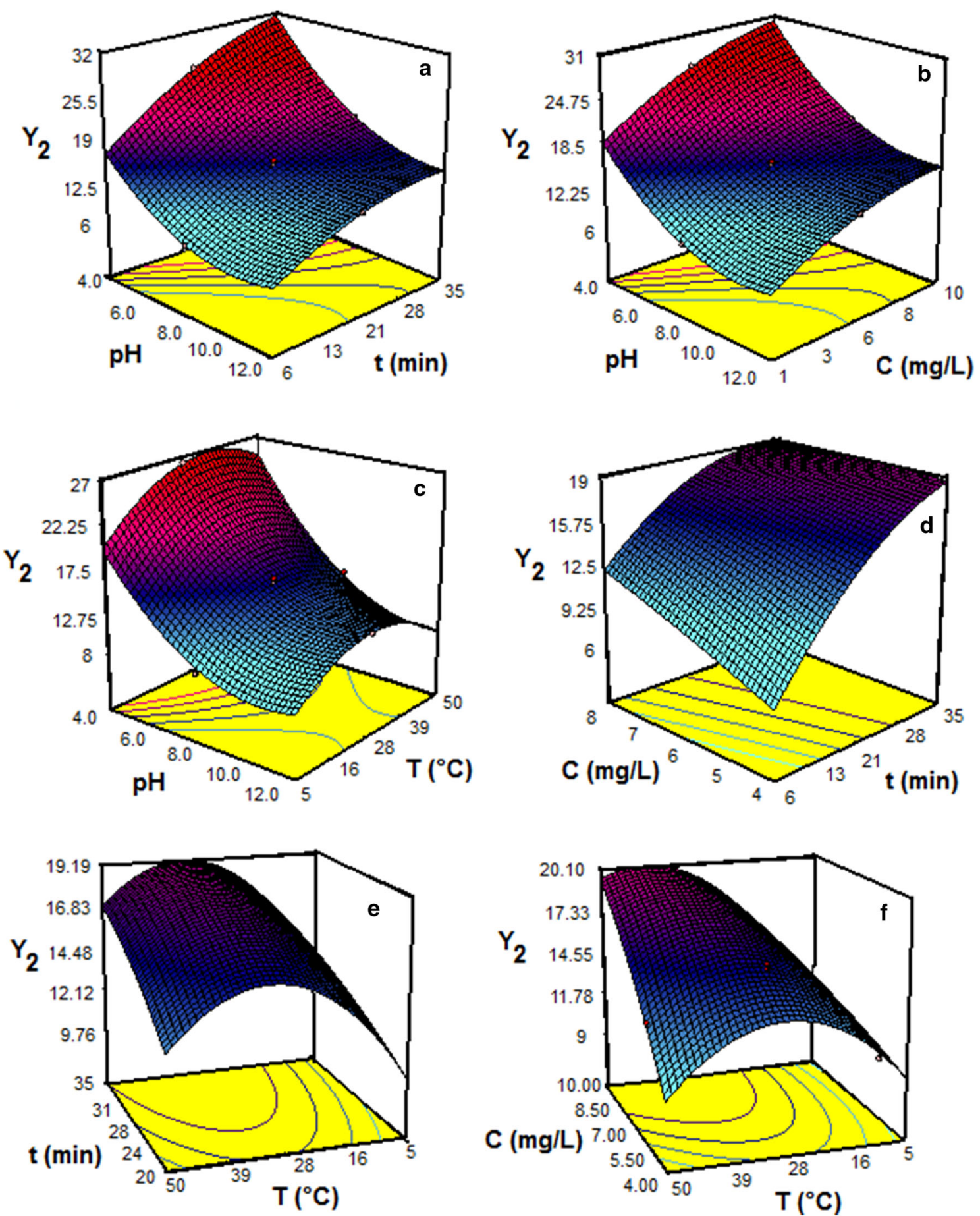

Fig. 10 Response surface plots related to the dye uptake by EMC (hold values: $\mathrm{pH}=8 ; T=27.5^{\circ} \mathrm{C} ; C=6 \mathrm{mg} / \mathrm{L} ; t=20.5 \mathrm{~min}$ )

$\Delta G_{T}^{0}=-R T \operatorname{Ln} K_{\mathrm{L}}[R$ : gas constant; $T$ : temperature $(\mathrm{K})]$. The change of $\Delta G_{T}^{0}$ versus temperature evolved linearly (Fig. 12), suggesting thus the heat $\left(\Delta H^{0}\right)$ and entropy $\left(\Delta S^{0}\right)$ of the adsorption process were almost constant in the considered range of temperatures. Given that $\Delta G_{T}^{0}=\Delta H^{0}$ $-T \Delta S^{0}$, it was derived that $\Delta \mathrm{H}^{0}=-19.326 \mathrm{~kJ} / \mathrm{mol}$ and $\Delta \mathrm{S}^{0}=0.0799 \mathrm{~kJ} / \mathrm{K}$ mol. These results allowed deducing that dye adsorption was a non-spontaneous and exothermic process, and disorder increased as a result of the dye species fixation. Moreover, adsorption took place by physisorption (no chemical change happened) since $\Delta \mathrm{H}^{0}<40 \mathrm{~kJ} / \mathrm{mol}$ (Shiau and Pan 2004).

As NC isotherms followed the Langmuir model, dye species adsorbed on like sites of sorbent particles without 

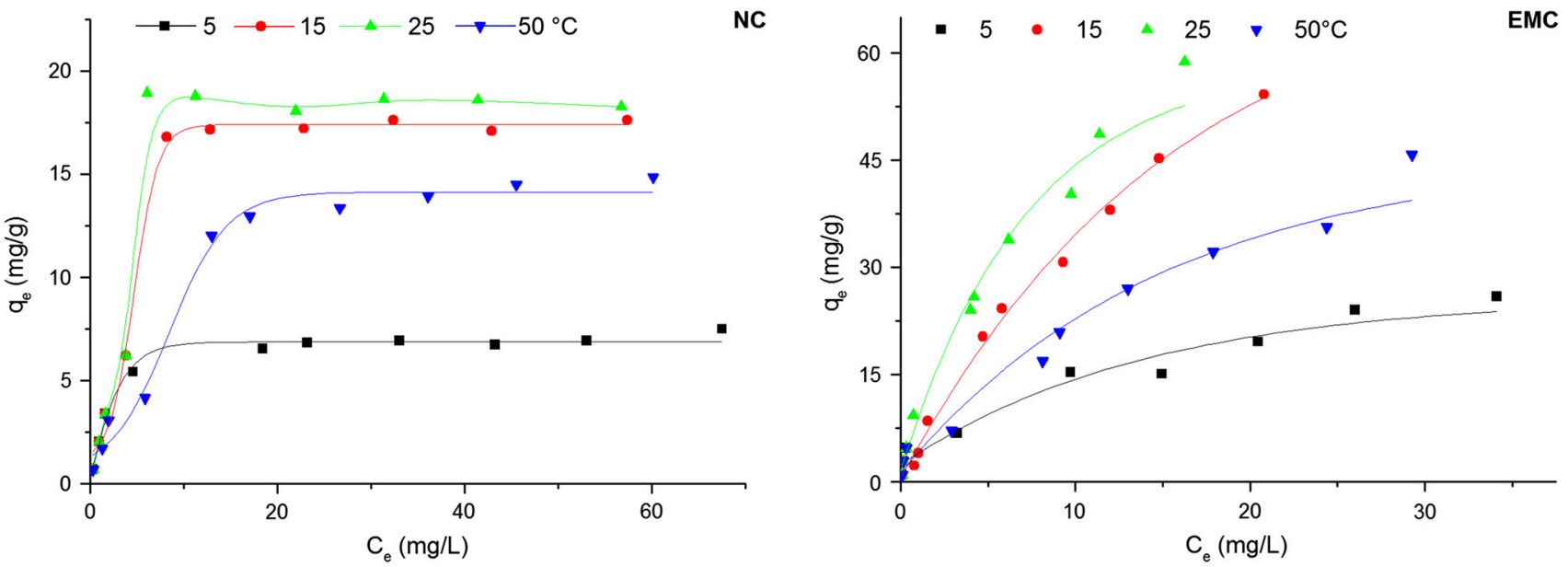

Fig. 11 Adsorption isotherms of NC and EMC sorbents

Table 8 Langmuir and Freundlich constants and fitting coefficients

\begin{tabular}{|c|c|c|c|c|c|c|c|c|c|c|c|c|}
\hline \multirow[t]{3}{*}{$T(\mathrm{~K})$} & \multicolumn{4}{|c|}{ Langmuir } & \multicolumn{4}{|c|}{ Freundlich } & \multicolumn{4}{|c|}{ Fitting coefficients } \\
\hline & \multicolumn{2}{|c|}{$K_{\mathrm{L}}(\mathrm{L} / \mathrm{mg})$} & \multicolumn{2}{|c|}{$q_{\mathrm{m}}(\mathrm{mg} / \mathrm{g})$} & \multicolumn{2}{|l|}{$K_{\mathrm{F}}$} & \multicolumn{2}{|l|}{$1 / n$} & \multicolumn{2}{|l|}{$\mathrm{L}$} & \multicolumn{2}{|l|}{$\mathrm{F}$} \\
\hline & $\mathrm{NC}$ & EMC & $\mathrm{NC}$ & EMC & $\mathrm{NC}$ & EMC & $\mathrm{NC}$ & EMC & $\mathrm{NC}$ & EMC & $\mathrm{NC}$ & EMC \\
\hline 278 & 0.37 & 0.19 & 7.48 & 26.88 & 1.89 & 4.86 & 0.38 & 0.47 & 0.998 & 0.953 & 0.914 & 0.963 \\
\hline 288 & 0.16 & 0.04 & 20.21 & 121.36 & 2.22 & 4.78 & 0.63 & 0.83 & 0.989 & 0.693 & 0.945 & 0.985 \\
\hline 298 & 0.155 & 0.16 & 21.39 & 74.52 & 2.35 & 8.65 & 0.64 & 0.73 & 0.985 & 0.956 & 0.926 & 0.985 \\
\hline 323 & 0.096 & 0.11 & 17.85 & 50.84 & 1.62 & 5.74 & 0.62 & 0.58 & 0.984 & 0.882 & 0.975 & 0.974 \\
\hline
\end{tabular}

Table 9 Marquardt's percent standard deviation (MPSD) determined for Langmuir and Freundlich isotherms related to NC and EMC sorbents

\begin{tabular}{llllll}
\hline \multirow{2}{*}{ Temperature (K) } & \multicolumn{2}{l}{ Langmuir } & & \multicolumn{2}{l}{ Freundlich } \\
\cline { 2 - 3 } & NC & EMC & & NC & EMC \\
\hline 278 & 10 & 48 & 37 & 36 \\
288 & 28 & 30 & 41 & 31 \\
298 & 33 & 21 & & 47 & 29 \\
323 & 23 & 48 & & 25 & 33 \\
\hline
\end{tabular}

interactions. Saturation happened as a monolayer of adsorbate formed. Likely because of the small thickness of the layer and the random distribution of dye species, the XRD pattern of the NC-Dye residue (Fig. 2) did not exhibit any peak associable to the dye, characterized by a wellcrystallized structure (Fig. 2). However, in the case of the EMC-D residue, some X-reflections of the dye were identified (Fig. 2). In this respect, it could be mentioned that because of bands overlapping, the IR bands of the eventual tied species of the dye could not be distinguished (Fig. 3). It was believed that thicken layers of dye molecules were built around EMC particles. These results concurred with the isotherms modeling since it was shown

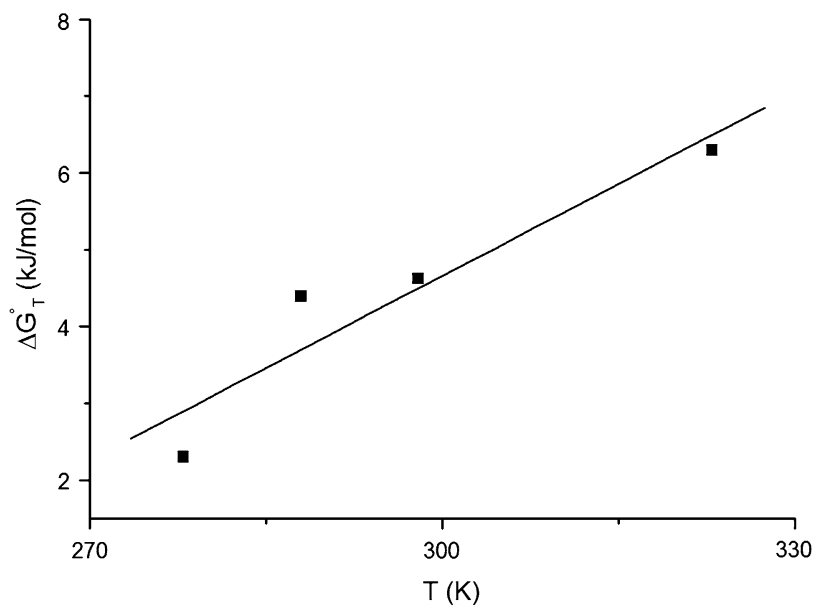

Fig. 12 Variation of the Gibbs free energy of the adsorption process of blue copper on $\mathrm{NC}$ versus operating temperature

that EMC isotherms followed the Freundlich equation, that is, adsorption happened on heterogeneous sites and dye layers built around solid particles. It seemed that, in the later case, active sites located on amorphous silica were involved in the adsorption process.

Because of their overall negative charges, dye species and clay particles should be the subject of repulsion, and 
adsorption should not occur. But, referring to the aforementioned kinetic study, the step relevant to the fixation of dye species on adsorbent particles was relatively rapid since the main controlling step was diffusion across the boundary liquid layer. Given the absence of exchangeable anion, adsorption likely happened, among others, on positive edge sites of the particles of montmorillonite. Considering the $\mathrm{NC}$ absorbent, the maximum retained amount as compared to CEC $\left(q_{\mathrm{m}} / \mathrm{CEC}\right)$ did not exceed about $2 \%$.

\section{Conclusions}

1. The electrochemical treatment of bentonite resulted in a partial dissolution of montmorillonite and ancillary minerals. The basal spacing of the clay mineral was quasi-constant, and the common aluminum sacrificial anode-derivative species were not detected.

2. The dye adsorption increased with the rise of the clay content. It however remained unchanged as the clay dose exceeded 7.8 and $6.5 \mathrm{~g} / \mathrm{L}$ of $\mathrm{NC}$ and EMC, respectively. Apparently, higher clay contents led to particles agglomeration.

3. In the range $5-50{ }^{\circ} \mathrm{C}$, the adsorption kinetics data for both sorbents were well described by the pseudo-firstorder equation. Divergences were observed in the kinetics rate-controlling steps.

4. The kinetics law varied with the change of $\mathrm{pH}$, and the rate constants for $\mathrm{NC}$ were always higher. At $4 \leq \mathrm{pH} \leq 12$, diffusion through the liquid film around particles of the sorbents was the rate-limiting step.

5. The NC isotherms well fitted the Langmuir model, and adsorption proceeded by physisorption. The heat involved in this process was $-19.326 \mathrm{~kJ} / \mathrm{mol}$. In the case of EMC, the isotherms well followed the Freundlich equation. However, this result was partially questionable by the use of the Marquardt's percent standard deviation.

6. The adoption of the polynomial model and the use of RSM allowed to express the variation of the dye uptake amount against the coded variables related to $\mathrm{pH}$, contact time, clay dose and temperature. In this respect, it may be concluded that apart from $\mathrm{pH}$, the increase of the considered factors had positive impacts on the uptake amount. Moreover, the most interactions between the factors were antagonistic.

Open Access This article is distributed under the terms of the Creative Commons Attribution License which permits any use, distribution, and reproduction in any medium, provided the original author(s) and the source are credited.

\section{References}

Albanis TA, Hela DG, Sakellarides TM, Danis TG (2000) Removal of dyes from aqueous solutions by adsorption on mixtures of fly ash and soil in batch and column techniques. Global Nest: Int J 2(3):237-244

Al-Degs YS, El-Barghouthi MI, Issa AA, Khraisheh MA, Walker GM (2006) Sorption of $\mathrm{Zn}$ (II), $\mathrm{Pb}$ (II), and $\mathrm{Co}$ (II) using natural sorbents: equilibrium and kinetic studies. Water Res 40:2645-2658

Aleboyeh A, Daneshvar N, Kasiri MB (2008) Optimization of C.I. Acid Red 14 azo dye removal by electrocoagulation batch process with response surface methodology. Chem Eng Process 47:827-832

Al-Ghouti MA, Khraisheh MAM, Allen SJ, Ahmad MN (2003) The removal of dyes from textile wastewater: a study of the physical characteristics and adsorption mechanisms of diatomaceous earth. J Environ Manage 69(3):229-238

Atun G, Hisarli G, Sheldrick WS, Muhler M (2003) Adsorptive removal of methylene blue from colored effluents of Fuller's earth. J Colloid Interface Sci 261:32-39

Crini G (2006) Non-conventional low-cost adsorbents for dye removal: a review. Bioresour Technol 97:1061-1085

Driouich H (1993) Prospections des argiles kaoliniques dans la région de Tassaout (Haut-Atlas). Ministère de l'énergie et des mines, Délégation régionale de Marrakech, Service Régionale de Géologie, Marrakech

Elwakeel KZ (2009) Removal of reactive black 5 from aqueous solutions using magnetic chitosan resins. J Hazard Mater 167:383-392

Elwakeel KZ, Abd El-Ghaffar MA, El-kousy SM, El-Shorbagy HG (2012) Synthesis of new ammonium chitosan derivatives and their application for dye removal from aqueous media. Chem Eng J 203:458-468

Ferreira SLC, Dos Santos WNL, Bezerra MA, Lemos VA, BosqueSendra JM (2003) Use of factorial design and Doehlert matrix for multivariate optimization of an on-line preconcentration system for lead determination by flame atomic absorption spectrometry. Anal Bioanal Chem 375:443-449

Gillman GP (2011) Charged clays: an environmental solution. Appl Clay Sci 53:361-365

Hajjaji M, Kacim S, Alami A, El Bouadili A, El Mountassir M (2001) Chemical and mineralogical characterization of a clay taken from the Moroccan Meseta and a study of the interaction between its fine fraction and methylene blue. Appl Clay Sci 20:1-12

Hajjaji M, Alami A, El Bouadili A (2006) Removal of methylene blue from aqueous solution by fibrous clay minerals. J Hazard Mater B135:188-192

Hall KR, Vermeylem T (1966) Pore and solid diffusion kinetics in fixed bed adsorption under constant pattern conditions. J Eng Chem Fundam 4:212-219

Hang PT, Brindley GW (1970) Methylene blue absorption by clay minerals. Determination of surface areas and cation exchange capacities (clay-organic studies X VIII). Clays Clay Miner 18:203-212

Ho YS, McKay G (1998) A comparison of chemisorptions kinetic models applied to pollutant removal on various sorbents. Trans IChemE 76:332-340

Ho YS, Ng JC, McKay G (2000) Kinetics of pollutants sorption by biosorbents: review. Sep Purif Methods 29:189-232

Holtzapffel T (1985) Les minéraux argileux- Préparation, analyse diffractométrique et détermination. Société Géologique du nord (France), Publication 12. ISSN 0291-3062

Khalfaoui A, Hajjaji M, Kacim S, Baçaoui A (2006) Evaluation of the simultaneous effects of firing cycle parameters on technological 
properties and ceramic suitability of a raw clay using the response surface methodology. J Am Ceram Soc 89:1563-1567

Kobya M, Can OT, Bayramoglu M (2003) Treatment of textile wastewaters by electrocoagulation using iron and aluminum electrodes. J Hazard Mater 100:163-178

Lagaly G, Ogawa M, Dékany I (2006) Clay mineral organic interactions. In: Bergaya F, Theng BKG, Lagaly G (eds) Handbook of clay science, developments in clay science, vol 1. Elsevier Ltd., Amsterdam, pp 309-377

Liu HL, Lan YW, Cheng YC (2004) Optimal production of sulphuric acid by Thiobacillus thiooxidans using response surface methodology. Process Biochem 39:1953-1961

McKay G, Ramprasad G, Mowli P (1987) Desorption and regeneration of dye colours from low-cost materials. Water Res 21(3):375-377

Picard T, Cathalifaud-Feuillade G, Mazet M, Vandensteendam C (2000) Cathodic dissolution in the electrocoagulation process using aluminum electrodes. J Environ Monit 2:77-80

Porter JF, McKay G, Choy KH (1999) The prediction of sorption from a binary mixture of acidic dyes using single- and mixedisotherm variants of the ideal adsorbed solute theory. Chem Eng Sci 54:5863-5885
Robinson T, Chandran B, Nigam P (2002) Effect of pretreatments of three waste residues, wheat straw, corncobs and bariey husks on dye adsorption. Bioresour Technol 85(2):119-124

Shiau CY, Pan CC (2004) Adsorption of basic dyes from aqueous solution by various adsorbents. Sep Sci Technol 39:1733-1750

Wang S, Boyjoo Y, Choueib A, Zhu ZH (2005) Removal of dyes from aqueous solution using fly ash and red mud. Water Res 39:129-138

Yariv S (2001) Staining of clay minerals and visible absorption spectroscopy of dye-clay complexes. In: Yariv S, Cross H (eds) Organo-clay complexes and interactions. Marcel Dekker, Inc., New York, pp 436-566

Yeddou N, Bensmaili A (2005) Kinetic models for the sorption of dye from aqueous solution by clay-wood sawdust mixture. Desalination 185:499-508

Yetilmezsoy K, Demirel S, Vanderbei RJ (2009) Response surface modeling of $\mathrm{Pb}$ (II) removal from aqueous solution by Pistacia vera L.: Box-Behnken experimental design. J Hazard Mater 171:551-562 